\title{
Investigations on a clinically and functionally unusual and novel germline p53 mutation
}

\section{J Rutherford', CE Chu², PM Duddy', RS Charlton², P Chumas ${ }^{3}$, GR Taylor ${ }^{2}$, X Lu', DM Barnes ${ }^{5}$ and RS Camplejohn*,I}

\begin{abstract}
'Richard Dimbleby Department Cancer Research, Guy's, King's and St Thomas' School of Medicine, St Thomas' Hospital, London SEI 7EH, UK; ${ }^{2}$ St James's University Hospital, Beckett Street, Leeds LS9 7TF, UK; ${ }^{3}$ The General Infirmary, Leeds LSI 3EX, UK; ${ }^{4}$ Ludwig Institute, St Mary's Hospital, Norfolk Place, London W2 IPG, UK; ${ }^{5}$ ICRF Clinical Oncology Unit, Guy's Hospital, London SEI 9RT, UK
\end{abstract}

This report describes an individual with a rare choroid plexus papilloma in adulthood (age 29) after earlier having an osteosarcoma (age 22). The results from this study, and others, suggest that it may be advisable to consider the possibility of a germline p53 mutation in adults presenting with choroid plexus tumours. In the current study automated DNA sequencing of genomic DNA detected a novel germline 7 base pair insertion in exon 5 of the p53 gene in this patient. The alteration in frame would produce amino acid substitutions beginning with alanine to glycine at position $|6|$ and a stop codon at position 182 in the mutated protein. Surprisingly two assays of p53 function gave apparently wild-type results on peripheral blood lymphocytes from this individual. These results led us to carry out more detailed functional tests on the mutant protein. The mutant allele was expressed either at very low levels or not at all in phytohaemagglutinin stimulated lymphocytes. Further, the mutant protein was completely non-functional in terms of its ability to transactivate a series of p53-responsive genes ( $p 21^{\text {WAFI }}$, bax, PIG3), to transrepress a target gene and to inhibit colony growth in transfected Saos-2 cells. However, surprisingly, data from irradiated peripheral blood lymphocytes and transfected Saos-2 cells, suggested that this truncated, mutant protein retains significant ability to induce apoptosis.

British Journal of Cancer (2002) 86, 1592 - 1596. DOI: 10.1038/sj/bjc/6600269 www.bjcancer.com

(c) 2002 Cancer Research UK

Keywords: p53; choroid plexus; Li Fraumeni

The tumour suppressor gene $p 53$ was discovered in 1979 because of its ability to bind to large T antigen (Lane and Crawford, 1979). p53 is a nuclear phosphoprotein that plays a central role in the cellular response to DNA damage by inducing either $\mathrm{G}_{1}$ arrest or apoptosis. It functions mainly through its ability to transactivate or repress target genes. Inactivation of wild-type p53 by mutation or interaction with cellular or viral proteins has been found to occur in over $50 \%$ of human cancers (Levine, 1997). Li-Fraumeni Syndrome (LFS), which is a rare dominantly inherited cancer predisposition syndrome, is associated with germline p53 mutations (Malkin et al, 1990). Individuals with LFS are at increased risk of developing a large spectrum of cancers, often with a very early onset and multiple primary tumours are common. Primary choroid plexus tumours are rare and usually occur in early childhood. However, several families with LFS have been described, in which there are individuals with choroid plexus tumours, sometimes in young adults (Garber et al, 1990). There have been four reports of germline $p 53$ mutations in families with LFS and childhood choroid plexus tumours (Frebourg et al, 1995; Jolly et al, 1994; Sedlacek et al, 1998; Vital et al, 1998). In this report we describe an adult patient with a novel germline 7 base pair insertion in the $p 53$ gene who presented with an osteosarcoma of the femur at the age of 22 years. This tumour was treated successfully

*Correspondence: RS Camplejohn; E-mail: r.camplejohn@cancer.org.uk Received 24 September 200 I; revised 19 February 2002; accepted I March 2002 by surgery and chemotherapy. At 29 years, she presented with a choroid plexus tumour which was shown on histology to be an atypical choroid plexus papilloma. There was no unusual family history of cancer (Figure 1) and both parents were alive and well in their 50s. Unexpectedly in routine screening this mutation appeared functional in two assays of p53 function (FASAY and apoptotic assay). The FASAY (Flaman et al, 1995) is a yeast based assay that looks at the transactivational ability of p53. This assay has been shown to reliably identify both germline (Lomax et al, 1997) and sporadic mutations (Duddy et al, 2000). The apoptotic assay (Camplejohn et al, 1995, 2000), can detect germline p53 mutations by measuring a reduction in the radiation-induced apoptotic response of peripheral blood lymphocytes (PBL) compared with that seen in cells from normal individuals. Due to the unexpected results in these two assays, further functional studies were carried out on this mutation, including an investigation of its ability to induce apoptosis in mammalian cells, to transrepress a target gene and to suppress colony growth.

\section{MATERIALS AND METHODS}

\section{Sequencing of DNA}

Genomic DNA was analysed from peripheral blood leukocytes by direct sequencing of double-stranded PCR products using the Big-Dye terminator kit (PE Applied Biosystems) for exons 5-9. Samples were analysed using a 377 sequencer with $36 \mathrm{~cm}$ plates. Sequences were read in both directions. Sequencing of plasmid 


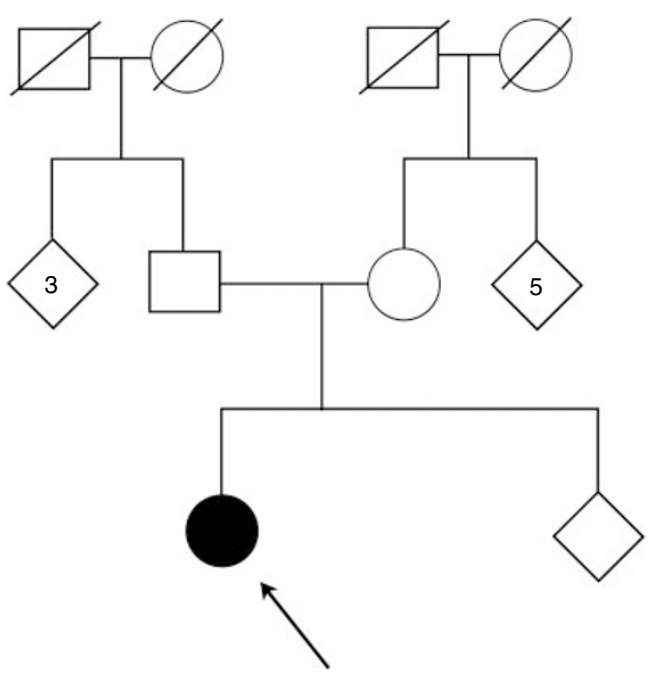

Figure I Patients family tree showing no excessive history of cancer. The proband is denoted by the arrow and the numbers ( 3 and 5 ) denote the number of unaffected siblings in the respective branches of the family tree.

and cDNA samples was carried out on a $\mathrm{ABI} 310$ sequencer (PE Applied Biosystems).

\section{Construction of the vectors}

For the transfection experiments, the different $p 53$ mutants ( 7 base pair insertion, 337C and 344P) were synthesized from wild-type p53 using the Quikchange site directed mutagenesis kit (Stratagene) and were cloned into the mammalian expression plasmid pC53SN3. The synthesised mutations were verified using automated sequencing. The $344 \mathrm{P}$ (Arg $\rightarrow$ Pro) mutation is functionally dead, whilst $337 \mathrm{C}(\mathrm{Arg} \rightarrow \mathrm{Cys})$ retains partial function and along with wild-type $p 53$ these two mutants were used as controls in the various assays. The FASAY vectors were kindly provided by Dr R Iggo, Dr JM Flaman and Dr T Frebourg.

\section{Cell culture and transfection}

Saos-2 cells were cultured in DMEM (ICRF Cell Services), supplemented with $4 \mathrm{~mm}$ L-glutamine (ICRF Cell Services) and 20\% FCS (PAA Laboratories $\mathrm{GmbH})$. Transfections were carried out in $10 \mathrm{~cm}$ dishes seeded with $8 \times 10^{5}$ cells, using $10 \mu \mathrm{g}$ DNA and the Profection Mammalian Transfection System-calcium phosphate kit (Promega), according to the manufacturer's instructions.

\section{Functional analysis for the separation of alleles in yeast (FASAY)}

The FASAY was carried out on wild-type $p 53,337 \mathrm{C}, 344 \mathrm{P}$ and the 7 base pair insertion containing plasmids as described by Lomax et al (1997). Briefly, the yeast strain yIG397 contains the vector pLS210 which has the selection gene Ade2 driven by a minimal promoter, CYC1. In the initial FASAY experiments the vector used has three copies of the p53 consensus binding sequence from the ribosomal gene cluster (RGC) immediately upstream of this minimal promoter. Subsequently, yeast containing similar vectors with the $\mathrm{p} 21$, bax and PIG3 p53 promoter binding sites respectively were used (Flaman et $a l, 1998)$. If the yeast cells are transformed with a wild-type $p 53$ gene (thus producing wild-type protein) the p53 protein binds to the RGC (or where relevant the $p 21^{W A F 1}$, bax or PIG3) consensus sequence, transactivating the Ade2 gene. If, however the $p 53$ gene has a mutation the resulting 533 protein cannot bind to the relevant consensus sequence and there is no transactivation of the Ade2 gene. In this case the yeast cells accumulate a red coloured intermediate of the adenine biosynthesis pathway.

\section{Apoptotic assay}

This assay was carried out as described by Camplejohn et al (1995). Briefly, PBL were separated from whole blood and cultured for 3 days, at which point half of the PBL were exposed to 4 Gy of radiation. Control and irradiated cells were cultured for a further $24 \mathrm{~h}$, when they were fixed in $70 \%$ ethanol. Prior to analysis the samples were acid denatured in $0.1 \mathrm{M} \mathrm{HCl}(\mathrm{BDH})$ and stained with propidium iodide (Sigma). The amount of apoptosis was measured by the size of the sub- $\mathrm{G}_{1}$ peak by FACS (FACSCalibur, Becton Dickinson).

\section{Western blotting}

For Western blotting, Saos- 2 cells were transfected as described and were lysed using NP40 lysis buffer (BDH) after $24 \mathrm{~h}$. The protein concentration was measured using the Bio-Rad DC assay (BioRad Laboratories) and $15 \mu \mathrm{g}$ of protein denatured in the presence of SDS was loaded onto a $12 \%$ SDS-PAGE gel. Proteins were transferred onto a nitrocellulose membrane (Amersham Life Science) and were detected using DO-1 antibody (Santa Cruz Biotechnology). The secondary antibody used was a rabbit anti mouse HRP (DAKO) and this was in turn detected using the ECL Western blotting detection reagent (Amersham Pharmacia Biotechnology).

\section{Induction of apoptosis in Saos-2 cells}

Cells were transfected as described using the calcium phosphate profection kit (Promega). Cells were washed after $16 \mathrm{~h}$ and cultured for a further $72 \mathrm{~h}$. The Saos- 2 cells were then fixed in $70 \%$ ethanol and were stained with propidium iodide (Sigma) and with anti-p53 monoclonal antibody DO-1 (Santa Cruz Biotechnology) for FACS analysis. Apoptosis was determined for both the p53-positive and p53-negative sub-populations by the sub- $G_{1}$ peak size and all samples were compared to the wild-type control.

\section{Transrepression}

$5 \times 10^{5}$ Saos- 2 cells were transfected in $60 \mathrm{~mm}$ dishes with $1 \mu \mathrm{g}$ pC53-SN3 (containing wild-type or mutant p53) and $5 \mu \mathrm{g}$ SV40 $\beta$-gal. Cells were washed after $16 \mathrm{~h}$ and then cultured for $24 \mathrm{~h}$ and washed in PBS. 1X reporter lysis buffer (Promega) was used to lyse the cells. We added $20 \mu \mathrm{l}$ lysate to $150 \mu \mathrm{l}$ chlorophenolred $\beta$-D-galactopyranoside (Boehringer Mannheim) in a 96-well plate, and this was incubated at $37^{\circ} \mathrm{C}$. Measurements of absorbance were recorded using a plate reader at $570 \mathrm{~nm}$ every $15 \mathrm{~min}$.

\section{Suppression of colony growth}

$1 \times 10^{5}$ Saos-2 cells were transfected in $60 \mathrm{~mm}$ dishes with $7 \mu \mathrm{g}$ pC53-SN3 (containing wild-type or mutant p53). Cells were washed after $16 \mathrm{~h}$ and were cultured for $48 \mathrm{~h}$. G418 (Calbiochem) at $400 \mu \mathrm{g} \mathrm{ml}^{-1}$ was then added to the media on each dish, and cells were cultured for 4 weeks. Cells were washed in PBS, fixed by adding $70 \%$ ethanol, and stained using $0.1 \%$ methylene blue. The number of colonies on each plate was counted.

\section{RESULTS}

\section{Genomic sequencing of DNA}

Genomic sequencing of DNA from PBL was carried out in both directions in two independent laboratories from exon 5 through 
to exon 9. A frameshift mutation, the result of a 7 base pair insertion, was discovered in exon 5 of the $p 53$ gene, after the first base of codon 161 (Figure 2). The alteration in frame would produce amino acid substitutions beginning with alanine to glycine at position 161 and a stop codon at position 182 in the mutated protein. The insertion, GCCATGG, was found to be a direct repeat of the 7 base pair sequence immediately upstream in the $p 53$ gene.

One of the proband's parents elected to have predictive testing and was found not to have the mutation. The other parent declined testing.

\section{FASAY results}

The FASAY is a yeast based functional assay, designed to investigate the ability of p53 to transactivate a target gene by binding to a consensus sequence from the ribosomal gene cluster. Wildtype p53 will result in white colonies in the FASAY and mutant p53 will give red colonies. mRNA from the patient's PBL was subjected to RT-PCR and the resulting cDNA was tested in the FASAY. The results show that only $3 \%$ red colonies were produced in this experiment, indicating a wild-type result (any value under $10 \%$ is considered wild-type). Wild-type p 53 gave $2 \%$ red colonies, a non-functional mutant $(344 \mathrm{P})$ gave a result of $100 \%$ red colonies, and a partially functional mutant (337C) resulted in 98\% pink colonies; all these results were as expected (Figure 3). The 7 base pair insertion mutation was then synthesised by site-directed mutagenesis and was put back into the FASAY. Red colonies (100\%) were obtained, which indicated that this mutant p53 could not transactivate the Ade2 gene by binding to the consensus site from the RGC. The difference between the two FASAY results (from PBL and site-directed mutagenesis) could be explained if the patient was expressing the mutant allele either not at all or at only very low levels. In this case the white colonies in the original FASAY using mRNA from the patient's PBL would result exclusively from the wild-type $p 53$ allele. The engineered mutated cDNA was then put into three more FASAYs, using yeast engineered with different p53 binding sites from the bax, p21 $1^{\text {WAFP }}$ and PIG3 promoters (Flaman et al, 1998). The $100 \%$ red colonies were obtained with all three binding sites (data not shown). The mutated p53 could not therefore transactivate $b a x, p 21^{W A F 1}$ or PIG3 in the FASAY.

\section{Apoptotic assay}

The apoptotic assay (Camplejohn et al, 1995) was carried out on PBL obtained from the patient. The assay investigates the ability of these cells to apoptose in response to radiation and measures the increase in apoptosis after exposure to $4 \mathrm{~Gy}$ radiation. Unexpectedly, the results showed a normal response with an increase in apoptosis of $46 \%$.

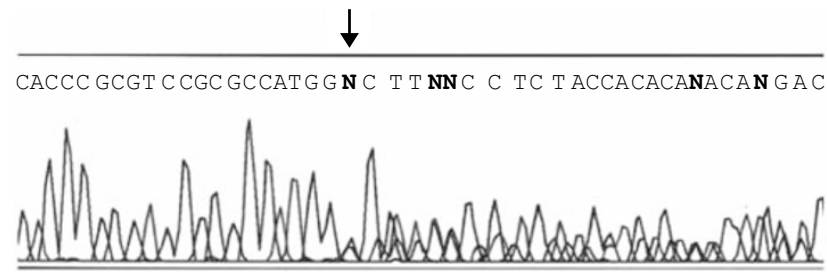

Figure 2 Genomic sequence. Analysis of genomic DNA was carried out from peripheral blood lymphocytes by direct sequencing of double stranded PCR products. A frameshift could be clearly seen starting after nucleotide 13160 in exon 5 (denoted by $\downarrow$ ). The insertion was found to be 7 base pairs in length and was a repeat of the 7 base pair sequence immediately before it. This frameshift would produce amino acid substitutions beginning with alanine to glycine at position $|6|$ and a stop at position $\mid 82$ Wild-type: CGCGCCATGGCCATCTA; Mutant: CGCGCCATGGGCCATGGCCATCTA

\section{Western blotting}

The manufactured 7 base pair insertion mutation was cloned into a mammalian expression plasmid and was transfected into Saos-2 cells. Cell lysates were made of these cells and of Saos-2 cells transfected with wild-type $p 53$. PHA stimulated lymphocytes from the patient were also lysed and a Western blot was run using all three lysates (Figure 4). The blot showed wild-type p53 with the expected size of $53 \mathrm{kDa}$ (lane 1). The lysate from the PHA stimulated lymphocytes also showed a band at $53 \mathrm{kDa}$ (lane 2). However, the Saos- 2 cells transfected with the 7 base pair mutation showed the presence of a truncated protein with a size of about $27 \mathrm{kDa}$. This corresponds to the predicted size of the mutated protein with a stop codon at position 182. The patient's lysate did not contain a band of this size, which again indicated that either the patient was not expressing detectable levels of the mutant allele or that PHA stimulating the lymphocytes favoured the wild-type allele.

mRNA from PHA stimulated lymphocytes was subjected to RT-PCR and the resulting cDNA was sequenced to try to detect the 7 base pair insertion. However, only wild-type sequence was obtained (data not shown).

\section{Induction of apoptosis}

Apoptosis in Saos- 2 cells can be induced by the expression of wildtype p53. Saos- 2 cells were transfected with the mammalian expression plasmid pC53-SN3, which contained the 7 base pair insertion mutation of $p 53$. Controls used included wild-type $p 53,337 \mathrm{C} p 53$ (a semi-functional mutant) and $344 \mathrm{P} p 53$. The results showed that the 7 base pair insertion mutation retains $65 \%$ of the ability to induce apoptosis compared with wild-type (Figure 5). The 344P mutation only retained about $20 \%$ of the activity of wild-type p53 and the 337C mutant retained about 55\%. Statistical analysis using both parametric (paired $t$-test) and non-parametric tests (Fisher's exact test) on these data showed that the 7 base pair insertion mutant was significantly different for apoptosis from both wild-type p53 and the 344P mutant, $(P<0.02)$. The 7 base pair mutation was not significantly different from the 337C mutant.

\section{Transrepression}

This method was carried out on the mutants described previously and involved co-transfection of the mammalian expression plasmid pC53-SN3 with a reporter construct consisting of an SV40 promoter upstream of the $\beta$-galactosidase gene. Wild-type p53 will repress the SV40 promoter and therefore will prevent the expression of $\beta$ galactosidase. Addition of a $\beta$-galactosidase substrate should produce no colour change. The results obtained in this assay, showed that the 7 base pair insertion mutant and the 344P mutant could not effectively repress the SV40 promoter (Figure 6). The $337 \mathrm{C}$ mutant retained about $50 \%$ of the ability of wild-type to repress the SV40 promoter.

\section{Suppression of growth}

Wild-type p53 can inhibit the growth of Saos-2 colonies and so a colony forming assay was carried out to determine the ability of the 7 base pair insertion to inhibit growth. Saos- 2 cells were again transfected with the pC53-SN3 expression plasmid, in order to observe which of the mutants could suppress the growth of colonies. The results showed that the 7 base pair insertion and the $344 \mathrm{P}$ mutants could not suppress the growth of colonies, compared to wild-type p53 (Figure 7).

\section{DISCUSSION}

The 7 base pair insertion is a novel mutation and is not recorded on the $p 53$ database. The mutation is suspected to be de novo, due 
FASAY results

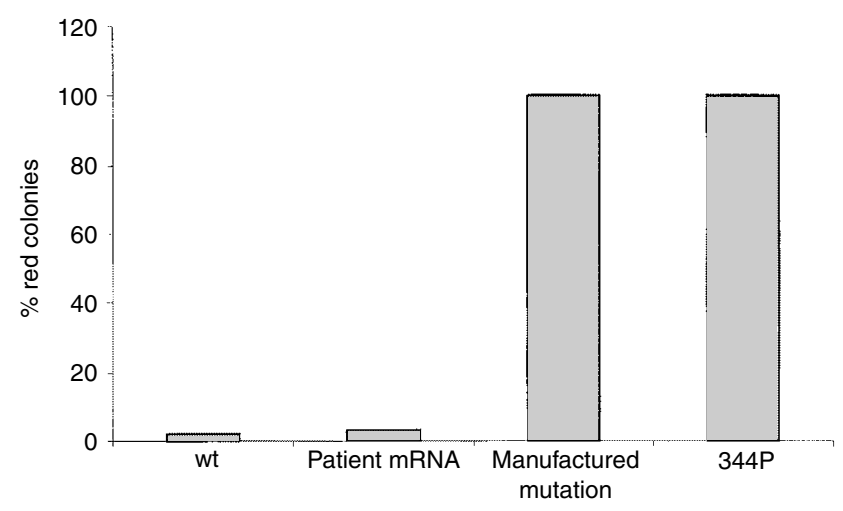

Figure 3 FASAY results. The FASAY gave a normal wild-type result with only $3 \%$ red colonies when mRNA was extracted from the patients PHAstimulated leukocytes. In contrast the 7 base pair mutation synthesised by site directed mutagenesis gave 100\% red colonies. The 344P mutation, which is an inactive mutant, also gave 100\% red colonies and wild-type p53 gave only $2 \%$ red colonies.

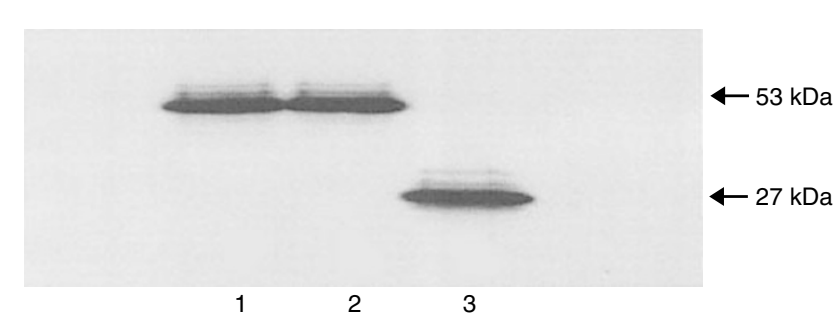

Figure 4 Western blot. The 7 base pair mutation was cloned into the mammalian expression plasmid pC53-SN3, which was transfected into Saos-2 cells. A Western blot was carried out using lysates from these cells, cells transfected with WT p53 and PHA stimulated lymphocytes from the patient. The blot showed WT p53 with the expected size of $53 \mathrm{kDa}$ (lane I) and the p53 from the patient's lymphocytes also at size $53 \mathrm{kDa}$ (lane 2). The cells transfected with the manufactured mutation showed a protein on the blot at about size $27 \mathrm{kDa}$ (lane 3).

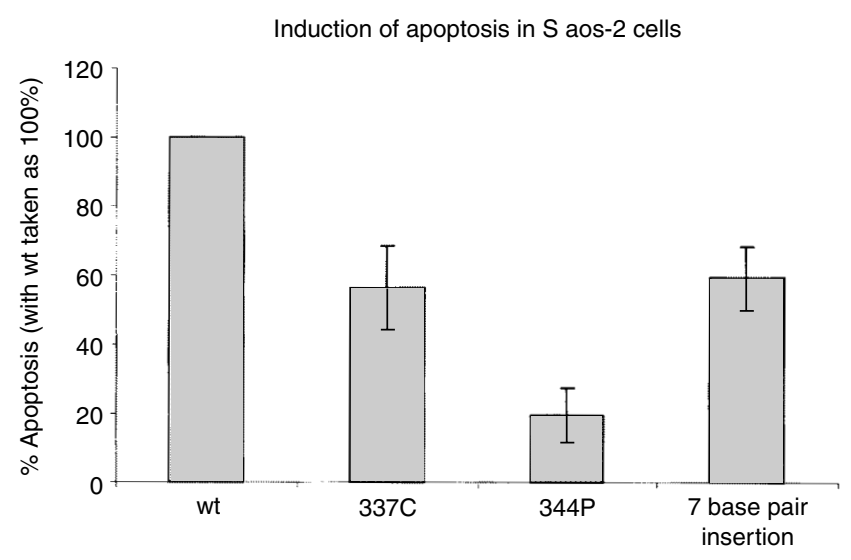

Figure 5 Induction of apoptosis. The pC53-SN3 plasmid containing the p53 insert of interest was transfected into Saos-2 cells, which were washed after $16 \mathrm{~h}$ and reincubated for $72 \mathrm{~h}$. The results show that the 7 base pair mutation retained about $65 \%$ of the apoptotic ability of WT p53. 344P, the non-functional mutant only retained about $20 \%$ apoptotic ability. Statistical analysis showed that the 7 base pair mutation was significantly different from both $344 \mathrm{P}$ and $\mathrm{WT}$, with $P<0.02$.

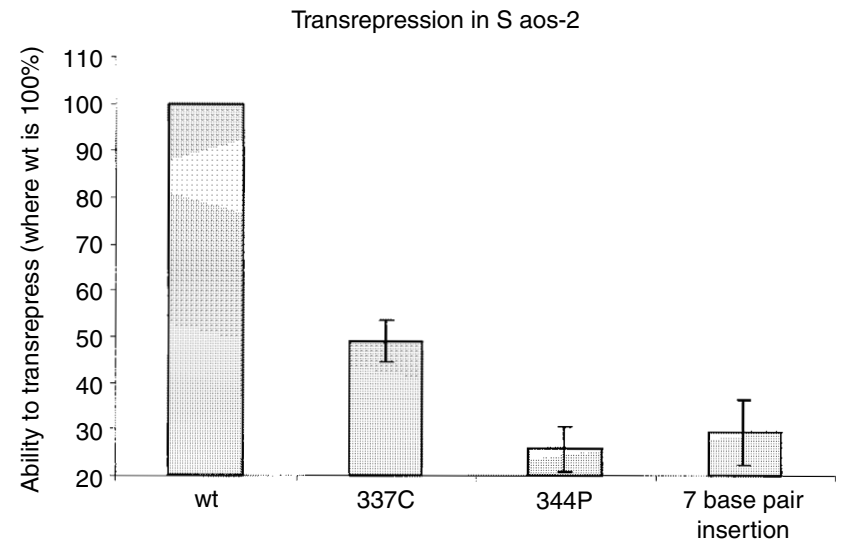

Figure 6 Transrepression. Saos-2 cells were transfected, with pC53-SN3 and pSV40- $\beta$ gal. Cells were washed after $16 \mathrm{~h}$ and lysed after a further $24 \mathrm{~h}$. The results show that the 7 base pair insertion is similar to 344P $(P=0.33)$, in that it cannot repress the SV40 promoter, whereas wild-type p53 can

Suppression of growth in S aos-2 cells

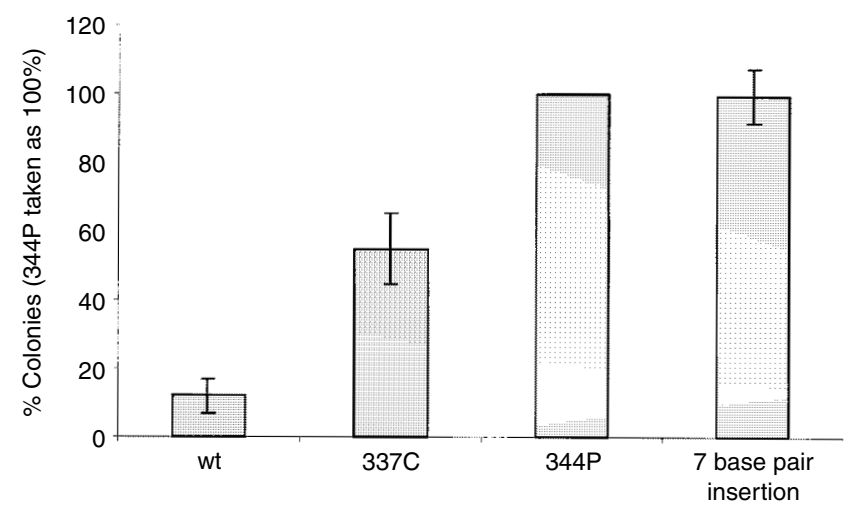

Figure 7 Suppression of growth. Saos-2 cells were transfected with pC53-SN3 as before, but were seeded at only $1 \times 10^{5}$ cells per $60 \mathrm{~mm}$ dish. Cells were washed $16 \mathrm{~h}$ after transfection and were treated with G4I8 at $400 \mu \mathrm{g} \mathrm{ml}^{-1}$ after $48 \mathrm{~h}$. The cells were left for 4 weeks and the number of colonies produced was then counted. The results show that the two mutant proteins (344P and the 7 base pair insertion) produced the most colonies in this experiment. Indeed, the number of colonies was identical for these two mutants. As the 344P mutant is known to be functionally dead, this demonstrates a complete lack of suppression of growth by the 7 base pair insertion mutation.

to the lack of family cancer history and the lack of mutation in the parent tested. The insertion being so large is unusual, as most reported insertions are between one and three base pairs. Cooper and Krawczak (1993) looked at 20 short insertions, nine of which were single base insertions. Two mechanisms for these insertions were proposed; they could be caused either by slipped mispair mediated by direct repeats (trinucleotide expansions) or mediated by inverted repeats (palindrome). The repeats stabilise a hairpin loop structure. The present reported insertion is a duplication of the previous 7 base pairs and occurs at a palindrome sequence of 8 base pairs.

An association between choroid plexus tumours and LFS has been suggested by others (Garber et al, 1990; Yuasa et al, 1993). Choroid plexus tumours are rare and are more common in childhood (Dohrmann and Collias, 1975). There have been three previous reports of adult onset choroid plexus tumours in families with multiple malignancies. Two of these were choroid plexus carcinomas, presenting at ages 16 and 27 (Li et al, 1988) and 
one, a choroid plexus papilloma, at age 29 (Faber, 1934). There have been only four previous reports of mutations in $p 53$ found in families with choroid plexus tumours (Jolly et al, 1994; Frebourg et al, 1995; Sedlacek et al, 1998; Vital et al, 1998). However, none of the previously reported mutations were insertions and the patients were all children.

The results from the first two functional assays carried out were normal (FASAY and Apoptotic assay). Further investigations were therefore carried out in order to characterise this mutation. The FASAY using the site-directed mutagenesis 7 base pair insertion cDNA gave an abnormal result (100\% red colonies). This result most likely indicated that the mutant allele is expressed at an undetectable level in the original FASAY carried out using mRNA from PHA stimulated PBL from the patient. However, the normal apoptotic response of the patient's cells was surprising as the presence of a non-expressed mutant allele would be expected to result in an abnormal apoptotic response. It is possible that stimulation by PHA of the lymphocytes favoured expression of the wild-type allele hence the wild-type result in the original FASAY. The lymphocytes used in the apoptotic assay are not treated with PHA and it is possible that both alleles were expressed at the very low levels seen normally in unstimulated PBL. This result would then be consistent with the ability of the 7 base pair insertion to induce apoptosis in Saos-2 cells. Western blotting of the patient's PHA stimulated lymphocytes gave a single band present at the expected size of $53 \mathrm{kDa}$. The transfected Saos-2 cells showed a band at about $27 \mathrm{kDa}$, which was the size expected for a truncated protein with a stop codon at position 182. No truncated protein was seen in PBL from the patient and sequencing of the mRNA showed no mutation. The induction of apoptosis results showed that the 7 base pair insertion mutation retained $65 \%$ of the ability of wild-type to induce apoptosis in Saos-2 cells. However, the mechanism by which a 182 amino acid truncated p53 protein can partially

\section{REFERENCES}

Camplejohn RS, Perry P, Hodgson SV, Turner G, Williams A, Upton C, MacGeoch C, Mohammed S, Barnes DM (1995) A possible screening test for inherited p53-related defects based on the apoptotic response of peripheral blood lymphocytes to DNA damage. Br J Cancer 72: 654-662

Camplejohn RS, Sodha N, Gilchrist R, Lomax ME, Duddy PM, Miner C, Alarcon-Gonzalez P, Barnes DM, Eeles RA (2000) The value of rapid functional assays of germline p53 status in LFS and LFL families. Br J Cancer 82: $1145-1148$

Cooper DN, Krawczak M (1993) Human Gene Mutation, Oxford, UK: BIOS Scientific Publishers

Dohrmann GJ, Collias JC (1975) Choroid plexus carcinoma. J Neurosurg 43: $225-232$

Duddy PM, Hanby AM, Barnes DM, Camplejohn RS (2000) Improving the detection of p53 mutations in breast cancer by use of the FASAY, a functional assay. I Mol Diagnost (Am J Pathol, Part B) 2: 139-144

Faber V (1934) Fall von carcinomatos entartetem Papillom des Seitenventrikels. Frankfurt Z Pathol 47: 168-172

Flaman JM, Frebourg T, Moreau V, Charbonnier F, Martin C, Chappuis P, Sappino AP, Limacher J-M, Bron L, Benhattar J, Tada M, Van Meir EG, Estreicher A, Iggo RD (1995) A simple p53 functional assay for screening cell lines, blood and tumours. PNAS 92: 3963-3967

Flaman JM, Robert V, Lenglet S, Moreau V, Iggo R, Frebourg T (1998) Identification of human p53 mutations with differential effects on the bax and p21 promoters using functional assays in yeast. Oncogene 16: 1369-1372

Frebourg T, Barbier N, Yan YX, Garber JE, Dreyfus M, Fraumeni J, Li FP, Friend SH (1995) Germ-line p53 mutations in 15 families with Li Fraumeni syndrome. Am J Hum Genet 56: 608-615

Garber JE, Burke EM, Lavally BL, Billett AL, Sallan SE, Scott RM, Kupsky W, Li FP (1990) Choroid plexus tumours in the breast cancer-sarcoma syndrome. Cancer 66: $2658-2660$

Haupt Y, Rowan S, Shaulian E, Vousden KH, Oren M (1995) Induction of apoptosis in HeLa cells by trans-activation-deficient p53. Genes Dev 9: $2170-2183$ induce apoptosis is not known. The studies on transactivation and transrepression in this report show the 7 base pair insertion mutation to be non-functional. The suppression of colony growth assay also showed the 7 base pair insertion mutation to be clearly inactive. However, in 1995 Haupt and colleagues reported a truncated protein, containing only the first 214 amino-terminal residues of murine p53, which was found to retain its ability to induce apoptosis in HeLa cells, but was transactivationally nonfunctional. These results are consistent with the findings described here for the 7 base pair insertion mutation. Wild-type p53induced apoptosis may involve the processes of transactivation or transrepression of target genes. However, an intriguing possibility has arisen following reports that p53 can play a pro-apoptotic role by binding directly to the mitochondrial membrane and interacting with protein members of the bcl-2 family (Marchenko et al, 2000). It was suggested by these latter authors that such binding might indeed be the mechanism by which the truncated protein described by Haupt et al (1995) induces apoptosis and the same could be true for the $7 \mathrm{bp}$ insertion mutation.

In summary, the 7 base pair insertion mutation is a novel and unusual mutation. The clinical details for the patient were unusual, with the occurrence of a choroid plexus tumour at 29 years. The $p 53$ mutation found in this individual is clearly functionally abnormal in terms of transactivation and transrepression of target genes and in suppression of colony growth. However, the normal results obtained for apoptosis induction in lymphocytes and the partial ability of the mutant to induce apoptosis in Saos-2 cells implies that a p53 protein with only half of the DNA binding domain present and no oligomerisation domain can retain significant ability to induce apoptosis. In terms of clinical significance it may be advisable to consider the possibility of germline $p 53$ mutations in adults presenting with choroid plexus tumours since it may influence decisions regarding treatment and imaging.
Jolly KW, Malkin D, Douglass EC, Brown TF, Sinclair AE, Look AT (1994) Splice-site mutation of the $p 53$ gene in a family with hereditary breastovarian cancer. Oncogene 9: 97-102

Lane DP, Crawford LV (1979) T antigen is bound to a host protein in SV40transformed cells. Nature 278: $261-263$

Levine AJ (1997) p53, the cellular gatekeeper for growth and division. Cell 88: $323-331$

Li FP, Fraumeni JF, Mulvihill JJ, Blattner WA, Dreyfus MG, Tucker MA, Miller RW (1988) A cancer family syndrome in twenty-four kindreds. Cancer Res 48: $5358-5362$

Lomax ME, Barnes DM, Gilchrist R, Picksley SM, Varley JM, Camplejohn RS (1997) Two functional assays employed to detect an unusual mutation in the oligomerisation domain of p53 in a Li-Fraumeni like family. Oncogene 14: $1869-1874$

Malkin D, Li FP, Strong LC, Fraumeni JF, Nelson CE, Kim DH, Kassel J, Gryka MA, Bischoff FZ, Tainsky MA, Friend SH (1990) Germline p53 mutations in a familial syndrome of breast cancer, sarcomas and other neoplasms. Science 250: $1233-1238$

Marchenko ND, Zaika A, Moll UM (2000) Death signal-induced localisation of p53 protein to mitochondria. J Biol Chem 275: 16202- 16212

Sedlacek Z, Kodet R, Kriz V, Seemanova E, Vodvarka P, Wilgenbus P, Mares J, Poustka A, Goetz P (1998) Two Li-Fraumeni syndrome families with novel germline p53 mutations: loss of the wild-type p53 allele in only 50\% of tumours. Br J Cancer 77: 1034-1039

Vital A, Bringuier P-P, Huang H, Galli FS, Rivel J, Ansoborlo S, Cazauran JM, Taillandier L, Kleihues P, Ohgaki H (1998) Astrocytomas and choroid plexus tumours in two families with identical $p 53$ germline mutations. $J$ Neuropathol Exp Neurol 57: $1061-1069$

Yuasa H, Tokito S, Tokunaga M (1993) Primary carcinoma of the choroid plexus in Li-Fraumeni syndrome: case report. Neurosurgery 32: 131-134 